|| ISSN(online): 2589-8698 || ISSN(print): 2589-868X || International Journal of Medical and Biomedical Studies

Available Online at www.ijmbs.info

PubMed (National Library of Medicine ID: 101738825)

Index Copernicus Value 2018: 75.71

Original Research Article

Volume 3, Issue 6; June: 2019; Page No. 28-32

\title{
SLEEP ASSESSMENT AND PERCEIVED STRESS AMONGST MEDICAL POSTGRADUATE RESIDENTS
}

\section{Jay Rajesh Ajgaonkar ${ }^{1}$, Mukta Pritam Bidikar ${ }^{2}$}

${ }^{1}$ III Year MBBS, Hinduhridaysamrat Balasaheb Thackrey Medical College and Dr. R.N. Cooper Hospital, Mumbai, Maharashtra, India.

${ }^{2}$ Assistant Professor, Department of Physiology, Hinduhridaysamrat Balasaheb Thackrey Medical College and Dr. R.N. Cooper Hospital, Mumbai, Maharashtra, India.

Article Info: Received 15 April 2019; Accepted 05 June. 2019

DOI: https://doi.org/10.32553/ijmbs.v3i6.287

Address for Correspondence: Dr. Mukta Pritam Bidikar, Assistant professor, Physiology department, HBT Medical College and Dr. R.N. Cooper Hospital, Mumbai, India.

Conflict of interest: No conflict of interest.

\section{Abstract}

Background: Medical graduates who enter into residency programmes form the backbone of the healthcare delivery system of the country. They are often expected to work for long hours which leads to sleep deprivation and increase in the perceived stress levels. Chronic sleep deprivation leads to destruction of sleep architecture. It may also compromise patient care. We examine the relationship between these two variables through this study. Material and methods: 50 resident doctors from different specialties of medicine were administered three validated questionnaires: the Epworth sleepiness scale (ESS), Pittsburgh sleep quality index (PSQI) and Cohen's perceived stress scale (PSS-10) to assess the daytime sleepiness, sleep quality and perceived stress levels respectively.

Result: A total of $56 \%$ residents reported greater than average scores on the ESS (Mean score $=11.02 \pm 5.5161$, Range $=1-24$ ). On the PSQI, 78\% residents reported poor sleep quality (Mean score $=6.98 \pm 3.146$, range $=0-15$ ) whereas on the PSS-10, $84 \%$ of the residents reported moderate to high levels of perceived stress (Mean score $=19.16 \pm 7.138$, range=3-37). Significant correlation was found between ESS and CPSS (Pearson coefficient $=0.4738, p<0.01$ ) as well as PSQI and CPSS (Pearson coefficient $=0.3024, p<0.05$ ). It is hypothesised that there is a causal relationship between daytime sleepiness perceived stress levels as well as sleep quality and perceived stress levels.

KEYWORDS: Sleep deprivation, Perceived stress, Stress levels, Epworth Sleepiness scale, sleep quality.

\section{Introduction:}

Average time available for nightly sleep is decreasing in the Global human population as a consequence of a more demanding life style. ${ }^{[1]}$ It is generally accepted that at least $20 \%$ of the World population experiences sleep loss or lives in a state of sleep debt. ${ }^{[2]}$ Sleep loss and sleep disorders are among the most common yet frequently overlooked and readily treatable health problems.

The sleep loss resulting from increased work load, shift work and various other challenges imposed by modern society may represent a serious threat for health and well-being. Sleep deprivation studies have revealed a variety of potentially harmful effects of sleep deprivation usually associated with increased stress, such as hypertension, diabetes, obesity, depression, heart attack and stroke. ${ }^{[3-7]}$ Also, total and partial sleep deprivation induce adverse changes in cognitive performance and quality of life. Research demonstrates that acquiring an appropriate amount of sleep is a fundamental component to work productivity. ${ }^{[8,9]}$

Sleep loss generally, in adults, refers to sleep of shorter duration than the average basal need of 7 to 8 hours per night and about 9 hours per night for adolescents. $^{[10]}$ Studies indicate that many adolescents do not obtain adequate nocturnal sleep and as many as one-fourth of adolescents report sleeping 6 hours or less per night. ${ }^{[11,12]}$

Medical students and residents are especially vulnerable population for sleep related disorders 
perhaps due to the long duration and high intensity of study, clinical duties that include overnight on-call duties, work that can be emotionally challenging and lifestyle choices. ${ }^{[13,14]}$ Sleep deprivation has been linked to subjective feelings of increased fatigue and decreased motivation in surgical house staff and medical students. However no significant changes were found in their capacity to learn and to retain new information concluding that there were no negative effects on the performance of this group. $^{[15,16]}$ Significant associations were observed between poor sleep quality, excessive daytime sleepiness, night time awakening and high perceived stress. ${ }^{[17]}$ Since the stress system plays a critical role in the adaptation to a challenging environment it is important to evaluate how this system is affected by sleep loss. There is paucity of research on sleep deprivation in Indian medical residents. These findings and the facts propelled us to do the present study to evaluate the extent of sleep deprivation and perceived stress levels in resident doctors.

Aims \& Objectives:

1. To determine sleep habits and sleep quality in medical residents using validated measures

2. To determine perceived stress in medical residents using validated measures.

3. To investigate associations of sleep deprivation with psychological stress.

\section{MATERIAL AND METHODS:}

Site: The study was conducted in the tertiary care teaching municipal hospital in Mumbai.

Sample size: 50 residents

Methodology:

Type of Study: Cross-sectional study

All experimental procedures were approved by the Ethics Committee and written informed consent of subjects was taken prior to their participation.

Subject selection criteria:

Resident doctors in the age group of 20-35 were selected.

Resident Doctors: This study population had completed medical graduation and were part of a medical team and were expected to being on call and actively participate in clinical care.

Exclusion Criteria:
1. Individuals with pre-existing conditions like sleep disorders.

2. Individuals undergoing psychiatric treatment currently.

3. Any other major medical or surgical illness

Questionnaire administration:

The questionnaire was used to collect the following information:

1. Demographic and lifestyle factors, including age, gender, clinical branch and year of study.

2. Basic clinical data: Vital parameters: pulse and blood pressure.

3. The Pittsburgh Sleep Quality Index: ${ }^{[18]}$

The PSQI asks 15 questions on the components of disturbed sleep and perceived quality of sleep. The response choices for this item will be as follows: very poor, fairly poor, fairly good or good. A score $\geq 5$ is indicative of poor sleep quality.

\section{The Epworth Sleepiness Scale: ${ }^{[19]}$}

The Epworth Sleepiness Scale is a valid and reliable instrument that is used to assess subjective daytime sleepiness. Individuals were asked to rate their chance of dozing off or falling asleep in 8 different situations or activities of daily living on a 4 point likert scale.

The sum of all 8 items produces a score (between 0 and 24 ) that reflects average sleep propensity.

0-5: Lower Normal Daytime Sleepiness

6-10: Higher Normal Daytime Sleepiness

11-12: Mild Excessive Daytime Sleepiness

13-15: Moderate Excessive Daytime Sleepiness

16-24: Severe Excessive Daytime Sleepiness

\section{Perceived Stress Scale: ${ }^{20}$}

Perceived stress scale is a valid, reliable and widely used psychological and psychiatric tool that measures a person's perception of stress during the previous month. The current study used the 10question version of the PSS-10. The residents rated their emotional and cognitive responses to specific circumstances in their daily lives on a 5-point Likert scale. The maximum score of the scale is 40 and higher scores reflect higher levels of stress and a greater likelihood that stress interferes with the participant's health. Participants' stress levels will be classified into following 3 categories: Low stress (PSS 
score $<12$ ), average stress (PSS score 12-15) and high stress (PSS score $>15$ ).

\section{Statistical Analysis:}

50 medical residents' data was collected and analysed using SPSS.

\section{RESULTS:}

Table 1: Basic characteristics of subjects taking part in the study

\begin{tabular}{|l|l|}
\hline Number of subjects & $\mathbf{5 0}$ \\
\hline Age $($ years $)$ & $27.24 \pm 2.245$ \\
\hline BMI $\left(\mathrm{kg} / \mathrm{m}^{2}\right)$ & $24.12 \pm 3.86$ \\
\hline
\end{tabular}

\section{Epworth sleepiness scale:}

The analysis showed that excessive daytime sleepiness was observed in $48 \%$ of the participating residents. Severe excessive daytime sleepiness was reported by $24 \%$ of the residents, while $14 \%$ had moderate excessive daytime sleepiness. Mild excessive daytime sleepiness was reported by $10 \%$ of residents. The mean ESS score was $11.02 \pm 5.5161$, range $=1-24$ indicating a significantly excessive propensity of sleepiness amongst the study population

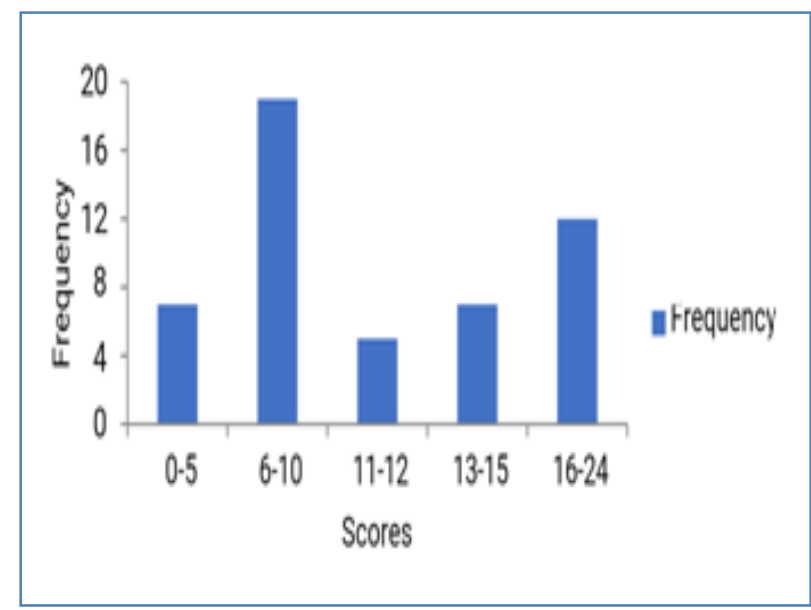

Figure 1: Epworth sleepiness scale

\section{Pittsburgh Sleep Quality Index:}

The other scale used was Pittsburgh Sleep Quality Index (PSQI) which showed that as much as $78 \%$ of the residents reported poor sleep quality. The mean PSQI score was $6.98 \pm 3.146$, Range $=0-15$. Figure 2 shows the scores of the questionnaire plotted against the frequency. The Pearson coefficient was $R=0.1564$, $(p=0.278)$ between ESS and PSQI scores, indicating a weakly positive correlation.

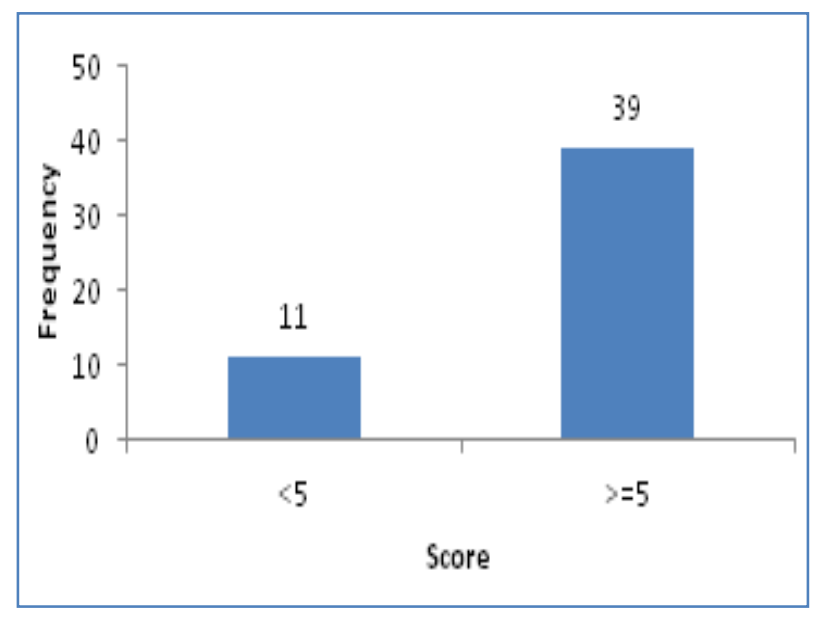

Figure 2: Pittsburgh sleep quality index

\section{Cohen's perceived stress scale:}

As many as $84 \%$ of the residents reported moderate to high levels of perceived stress on the Cohen's perceived stress scale (Fig.3). Of these, $16 \%$ were found to be in the high perceived stress category. Perceived stress is important because the perception of stress of what is happening in one's life is the most important in determining the harmful effects of stress on the person. Mean perceived stress $=19.16 \pm$ 7.138 , range $=3-37$

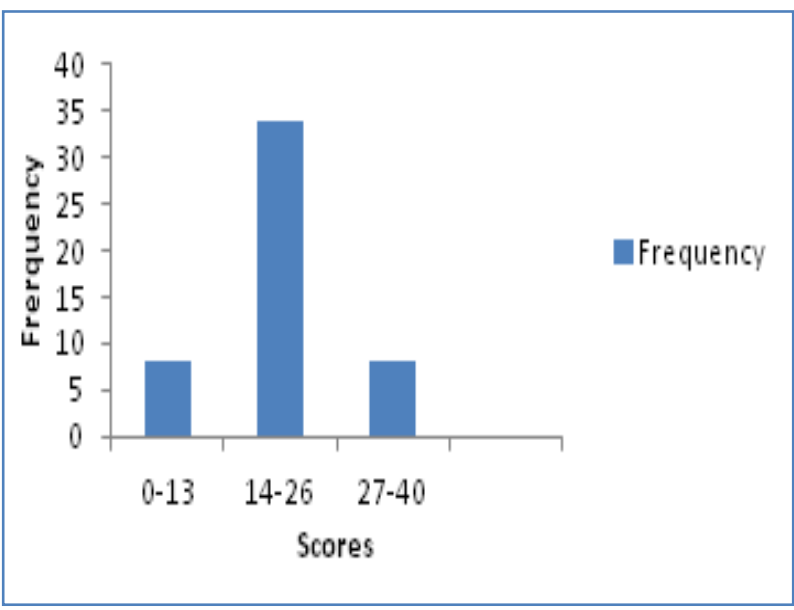

Figure 3: Cohen's perceived stress scale

Pearson coefficient between ESS and CPSS $=0.4738$ $(p<0.01)$ thus indicating a significant relationship between daytime sleepiness and perceived stress. Pearson Coefficient between PSQI and CPSS $=0.3024$ $(p<0.05)$ which indicates that lower levels of sleep quality were associated significantly with higher levels of perceived stress. Higher PSQI scores indicate lower sleep quality as well as quantity as the number of hours of sleep is also a component. 


\section{DISCUSSION:}

The study aimed to assess the resident's sleepiness and stress levels. Few studies have linked these two categories especially in India. Regarding the sleepiness of participants, $56 \%$ were found to be excessively sleepy on the Epworth Sleepiness Scale and would require seeking medical attention. Alami et al. ${ }^{[21]}$ studied the Epworth sleepiness scale and quality of life in medical residents. They reported a score of $\geq 10$ indicating daytime_sleepiness scale in $37.6 \%$ participants. A significant correlation was also found between sleepiness and quality of health of residents. Siddalingaiah HS et al. ${ }^{[22]}$ found excessive daytime sleepiness in 350 residents assessed using Epworth sleepiness scale and sleep hygiene index. In the present study as much as $78 \%$ residents reported poor sleep quality on PSQI. Nishida M et al. ${ }^{[23]}$ found that the residents' ability to perform relatively simple procedures like withdrawing blood was significantly impaired following night duty, where significant acute sleep deprivation was present, as tested by the ESS and PSQI. Min, A. A. et al ${ }^{[24]}$ reported that chronic decline in sleep quality leads to significant decrease in the psychological wellbeing of the residents. This is mostly due to longer duty hours which are related to the level of depression amongst medical resident doctors $^{[25]}$. A higher value was also found for perceived stress in $84 \%$ of residents. Life of medical resident and medical professional can be stressful. Different levels of stress from mild to severe have been reported in previous studies. ${ }^{[26]}$

We also found significant correlation between sleep deprivation and perceived stress levels of residents. Baldwin DC et al. ${ }^{[27]}$ reported that sleep deprivation and resulting fatigue are pervasive consequences of the high demands of a substantial number of residency training programs.

\section{CONCLUSION:}

It can be said that the sleep habits amongst the residents were found to be largely unhealthy resulting in high levels of perceived stress. This would not only put the residents at risk for various lifestyle disorders like cardiac diseases, hypertension, stroke and diabetes mellitus, but also impair their ability to deliver good quality healthcare manifesting in the form of increased errors. ${ }^{[28]}$ Furthermore, it could harm the patients because of the effects of sleep and stress on residents' cognition, co-ordination and memory. It is also associated with adverse effects on doctor-patient relationship and interpersonal relations between doctors ${ }^{[29]}$. The limitations of study were sample size and study on larger sample size would be required to further validate our findings. Use of more standardized techniques and questionnaires to evaluate sleep deprivation and stress in residents and other causes of stress also need to be explored for establishing correlation between sleep deprivation and stress.

\section{REFERENCES:}

1. Sleep Deprivation: Basic Science, Physiology and Behaviour. Monograph Lung Biology in health and Disease; Sleep, Kushida Vol. 1922005.

2. Rajaratnam SMW, Ardent J. Health in a 24-hour society. The Lancet 2001; 358: 999-1005.

3. Institute of Medicine (US) Committee on Sleep Medicine and Research; Colten HR, Altevogt BM, editors. Sleep Disorders and Sleep Deprivation: An Unmet Public Health Problem. Washington (DC): National Academies Press (US); 2006. 3, Extent and Health Consequences of Chronic Sleep Loss and SleepDisorders. Availablefrom: https://www.ncbi.nlm.nih.gov/books/NBK1996/

4. Al-Delaimy WK, Manson JE, Willett WC, Stampfer MJ, Hu FB. Snoring as a risk factor for type II diabetes mellitus: A prospective study. American Journal of Epidemiology. 2002;155(5):387-393.

5. Ayas NT, White DP, Manson JE, Stampfer MJ, Speizer FE, Malhotra A, Hu FB. A prospective study of sleep duration and coronary heart disease in women. Archives of Internal Medicine. 2003;163(2):205-209. [PubMed]

6. Babu AR, Herdegen J, Fogelfeld L, Shott S, Mazzone T. Type 2 diabetes, glycemic control, and continuous positive airway pressure in obstructive sleep apnea. Archives of Internal Medicine. 2005;165(4):447-452. [PubMed]

7. Bassetti C, Aldrich MS. Sleep apnea in acute cerebrovascular diseases: Final report on 128 patients. Sleep. 1999;22(2):217-223.

8. Alhola, P., \& Polo-Kantola, P. (2007). Sleep deprivation: Impact on cognitive performance Neuropsychiatric Disease and Treatment, 3(5), 553-567.

9. Takahashi M. Prioritizing sleep for healthy work schedules. Journal of physiological anthropology. 2012 Mar 13;31(1):1

10. Carskadon MA, Orav EJ, Dement WC. Evolution of sleep and daytime sleepness in adolescents. Sleep/Wake Disorders: Natural History, Epidemiology, and Long-Term Evolution. New York: Raven Press; 1983. 
11. Morrison DN, McGee R, Stanton WR. Sleep problems in adolescence. Journal of American Academy of Child \& Adolescents Psychiatry 1992;31:94-99.

12. Wolfson AR. Sleeping patterns of children and adolescents: Developmental trends, disruptions and adaptations. Child Adolescents Psychiatry Clinics North America. 1996;5:549-568.

13. Millman RP. Working Group on Sleepiness in Adolescents/Young Adults, AAP Committee on Adolescence. Excessive sleepiness in adolescents and young adults: Causes, consequences, and treatment strategies. Pediatrics. 2005;115(6):1774-1786.

14. Carskadon MA. Factors influencing sleep patterns of adolescents. In: Carskadon MA, editor. Adolescent sleep patterns: Biological, social, and psychological influences. New York: Cambridge University Press; 2002. pp. 4-26.

15. Browne BJ, Van Susteren $T$, Onsager DR, Simpson $D$, Salaymeh B, Condon RE. Influence of sleep deprivation on learning among surgical house staff and medical students. Surgery. 1994 May;115(5):604-10.

16. Ficke JH, Wiest $\mathrm{GH}$, Hahn EG. Are snoring students more likely to fail their exams? Meeting Abstracts of the American Lung Association /American Thoracic Society International Conference April 24-29, 1998.

17. Alsaggaf MA, Wali SO, Merdad RA, Merdad LA. Sleep quantity, quality, and insomnia symptoms of medical students during clinical years: Relationship with stress and academic performance. Saudi medical journal. 2016 Feb;37(2):173.

18. Buysse,D.J., Reynolds,C.F., Monk,T.H., Berman,S.R., \& Kupfer,D.J. (1989). The Pittsburgh Sleep Quality Index (PSQI): A new instrument for psychiatric research and practice. Psychiatry Research, 28(2), 193-213.

19. https://epworthsleepinessscale.com/

20. Cohen S, Kamarck T, Mermelstein R. Perceived stress scale. Measuring stress: A guide for health and social scientists. 1994.

21. Alami, Y. Z., Ghanim, B. T., \& Zyoud, S. H. (2018). Epworth sleepiness scale in medical residents: quality of sleep and its relationship to quality of life. Journal of Occupational Medicine and
Toxicology (London, England), 13, 21. https://doi.org/10.1186/s12995-018-0203-z

22. Siddalingaiah HS, Mastin DF, Moore BD, Bryson WJ, Chandrakala D, Singh A. Prevalence and determinants of excessive daytime sleepiness among resident doctors at a tertiary care institution in India. International Journal of Community Medicine And Public Health. 2018 Mar 23;5(4):1407-13.

23. Nishida, M., Kikuchi, S., Miwakeichi, F., \& Suda, S. (2017). Night duty and decreased brain activity of medical residents: a wearable optical topography study. Medical Education Online, 22(1), 1379345. https://doi.org/10.1080/ 10872981.2017.1379345

24. Min, A. A., Sbarra, D. A., \& Keim, S. M. (2015). Sleep disturbances predict prospective declines in resident physicians' psychological well-being. Medical Education Online, 20, 28530. https://doi.org/10.3402/meo.v20.28530

25. Grover, S., Sahoo, S., Bhalla, A., \& Avasthi, A. (2018). Psychological problems and burnout among medical professionals of a tertiary care hospital of North India: A cross-sectional study. Indian Journal of Psychiatry, 60(2), 175-188. https://doi.org/10.4103/psychiatry.IndianJPsychi atry_254_17

26. Shah M, Hasan S, Malik S, Sreeramareddy CT. Perceived stress, sources and severity of stress among medical undergraduates in a Pakistani medical school. BMC medical education. 2010 Dec;10(1):2.

27. Baldwin Jr DC, Daugherty SR. Sleep deprivation and fatigue in residency training: results of a national survey of first-and second-year residents. Sleep. 2004 Mar 15;27(2):217-23.

28. Ogawa, R., Seo, E., Maeno, T., Ito, M., Sanuki, M., \& Maeno, T. (2018). The relationship between long working hours and depression among firstyear residents in Japan. BMC Medical Education, 18(1), 50. https://doi.org/10.1186/s12909-0181171-9

29. Kalmbach, D. A., Arnedt, J. T., Song, P. X., Guille, C., \& Sen, S. (2017). Sleep Disturbance and Short Sleep as Risk Factors for Depression and Perceived Medical Errors in First-Year Residents. Sleep, 40(3). https://doi.org/10.1093/sleep/zsw 073 